\title{
Criminologia: Uma Visão Geral E Contemporânea Na Sociedade Brasileira
}

\author{
Paulo Rogério Ferreira de Lima
}

Bacharel em Direito, graduado pela Universidade Veiga de Almeida- RJ.

\section{Resumo}

O objetivo do presente artigo é trazer algumas considerações sobre a evolução da pena e a história da criminologia, procurando destacar as posições da escola clássica e positiva. A preocupação com essa temática visa o surgimento da criminologia e seus objetos de acordo com os pensadores da escola positiva e os dias atuais. A tríplice aliança entre a criminologia, direito penal e política criminal.

É nesta concepção que abordo a compreensão do processo evolutivo até chegar à importância das políticas criminais, abordando o crime e o controle social no Brasil. A relevância do policiamento comunitário para a sociedade como meio de controle e das medidas das políticas criminais. Para tanto, no primeiro momento, aborda-se a posição da escola clássica e positiva até chegar à criminologia dos dias atuais.

Palavras-chave: Criminologia; objetos crime e controle social; política criminal; policiamento comunitário.

Introdução

A conduta humana em uma ou outra direção e o livre arbítrio na escolha entre o bem ou mal mostram as existentes formas de viver do homem junto ao cunho social.
Os estudos bíblicos apontam que Deus ao colocar o homem no jardim do Éden, deu livre arbítrio de escolha e advertiu-o para não se entregar ao pecado. Por sua cobiça, o homem acabou conhecendo o bem e o mal através do fruto da árvore proibida. 
Outro apontamento bíblico foi a morte de Abel por Caim que, no tocante à evolução do homem na sociedade, já mostrava a predisposição agressiva do homem para o cometimento de crimes por diversos fatores impulsionadores.

Diante disto, se parte da premissa que o ser humano tem suas fraquezas, sendo a principal delas a livre escolha de decidir entre o bem e o mal junto com as vastas tentações da vida. Dentre estas, as cobiças do poder "ter" ou "ser", da vaidade, da ganância, da inveja, da ira, das paixões destrutivas, que semeiam um retrocesso na sua ordem moral e contribuem para um abismo criminal.

Sabendo que o estudo da criminologia abrange todas as questões que venham contribuir para a existência da criminalidade, se torna importante a existência de um estudo que aponte este fenômeno.

O estudo do comportamento humano deve ser analisado na ciência criminológica. As pesquisas mais pertinentes devem ser concentradas na conduta do delinquente, já que sua personalidade atua em diversas causas, muitas delas de formas ocultas até a ocorrência do ato delituoso.

Ao longo do tempo, a criminologia vem sendo subdividida em diversos progressos, dentre eles: a Biologia Criminal, Sociologia Criminal, Psicologia Criminal, Psiquiatria criminal e etc. Entende-se que tais ciências se prestam ao aspecto didático-pedagógico.
Seguindo este raciocínio, Newton e Walter Fernandes argumentam que a criminologia é " $a$ fusão de todas essas ciências em uma só". Daí surgindo a interdisciplinariedade da mesma, como uma ciência forte, influente, importante e estável em sua própria terminologia.

\section{Principais Apontamentos Históricos E A Evolução}

O chamado período da vingança, nascendo de um absolutismo europeu, também vigorou no Brasil durante o séc XV e XVI, e consistia numa monarquia absoluta, onde era pregado um sistema penal caótico, arbitrário e cruel, sem previsões dos direitos fundamentais, tendo como regra as penas de mortes ou penas execráveis.

A chamada vingança divina subdividiuse em: vingança privada, divina e pública.

A chamada vingança Privada foi a denominada lei de talião, onde vigorava a tese filosófica do "olho por olho, dente por dente" e o titular do jus puniendi era a vítima. Nesse período vigorava exercício das próprias razões.

Já na vingança divina, a igreja como titular do jus puniendi usava seus sacerdotes para aplicarem as penas em nome de Deus. Nesse período o fogo era considerado o elemento purificador da alma e a forma de aferir o grau de culpabilidade do delinquente se dava por meio de ordálias. 
Na vingança pública, conhecida na época como o ciclo do terror, o titular do jus puniendi era o monarca, onde este fazia o que bem entendia conforme suas razões e vontade. Foi marcado como um período cruel, arbitrário, onde as penas eram produzidas através de enforcamento, guilhotina, confisco de bens, apedrejamento e etc.

A partir da revolução do iluminismo, período chancelado como humanista, foi derrubada a monarquia, fazendo surgir o Estado liberal (século XVI e XVII). Esta época foi marcada pela forte atuação dos pensadores John Locke, Rousseau e Montesquieu, que contestavam as ideais absolutistas.

A ocorrência da substituição da emoção pela razão, ou seja, a aplicação da justiça no lugar da arbitrariedade, deu surgimento à então Escola clássica do direito penal.

A escola clássica, conhecida como etapa pré-científica da criminologia, tinha uma metodologia apriorística de estudo e era dogmática, baseando-se em hipóteses, deduções ou suposições. Para os pesquisadores positivistas, o método lógico-dedutivo dos clássicos era vago e meramente especulativo.

O principal impulsionador filosófico da escola clássica foi o jornalista italiano Cesare Bonesana, mais conhecido como Marquês de Beccaria, com sua obra "Dos Delitos e Das Penas"1764. Sua grande marca foi a defesa da humanização da pena e a limitação da atuação do
Estado, contrariando as injustiças e suas arbitrariedades.

Outro que veio repercutir na escola clássica foi Francesco Carrara, renomado jurista da época e defensor da tese que o homem deve ser submetido às leis penais por sua natureza moral.

Carrara iniciou a fase jurídica na escola clássica. Ele defendia o crime como um ente jurídico e o apontava como uma infração da lei do Estado, atingindo a segurança social. Para ele só era considerado crime o fato que infringisse a lei penal do Estado.

Podemos concluir então que a escola clássica teve duas vertentes, a fase filosófica (Beccaria) e jurídica (Carrara).

Vale ressaltar que na época já se estudava o sistema Penitenciário (Penologia), através de seu idealizador John Howard, sua obra: “The State of prisons", onde visava à melhoria das prisões, sendo antagônico à permanência do encarcerado que já havia cumprido a sua pena.

No período científico, surge o positivismo criminológico trifásico (antropológico, sociológico e jurídico). Para esta escola, a pena do delito é o meio de defesa do âmbito social, não só operando de modo repressivo, mas também de modo curativo e reeducativo.

O positivismo antropológico criminal teve como seu precursor o médico psiquiatra Cesar Lombroso, considerado até os dias atuais 
como o patrono da criminologia, cuja obra foi "O homem delinqüiente - Milão 1876". Nesta, considerou o delito como um fator natural do individuo associado a causas biológicas de natureza especialmente hereditária.

\section{A Teoria Da Delinquência Nata}

Lombroso adotava um método empírico de estudo e acreditava que a delinquência era um fator genético, ou seja, já nascia com o individuo.

De acordo com essa teoria, os delinquentes natos eram identificados por determinados traços físicos e psíquicos (estigmas de degeneralização). Ex: Protuberância occipital, testa fugida, polidactia, instabilidade de humor, insensibilidade a dor (justificando as tatuagens) e etc. Estes indivíduos seriam tendentes biologicamente a praticar determinados crimes. É o tipo atávico, ou seja, aqueles que representam uma regressão primitiva humana (homo sapiens).

Vale ressaltar que, em 1856, Mendel comprovou cientificamente a transmissão da carga hereditária. Assim, o reconhecimento da genes criminal através de fatores morfológicos, biológicos e psicológicos foram determinantes para a investigação do comportamento delitivo, concluindo que a teoria de Lombroso tinha fundamento.

O grande fator negativo de Cesare Lombroso foi propagar a generalização de que a delinquência vinha somente da genes do homem.

Mais tarde, anos defendendo seus estudos antropológicos e generalizando a sua teoria sem específicas comprovações, Lombroso foi veemente questionado por Enrico Ferri, seu aluno na época. Só em 1906 mudou sua concepção e admitiu outros fatores determinantes para a delinquência, como o fator sociológico adotado por Ferri.

Lombroso ainda classificava os delinquentes em: delinquente nato, delinquente louco, delinquente de ocasião e delinquente por paixão.

No Brasil, esses estudos foram mimetizados pelo médico legista, psiquiatra e antropólogo, Raimundo Nina Rodrigues, mais conhecido como Lombroso dos Trópicos, autor da obra: "As raças humanas e a Responsabilidade Penal no Brasil-1984".

Nina Rodrigues defendia com ímpeto a segregação racial e foi contra o abolicionismo da escravidão. Argumentava a tese de um código penal destinado a raças diferentes (negros e mestiços), que dentre muitos estudos plausíveis, este foi uma negativa que ajudou a propagar atos meramente racistas que refletem nos dias atuais.

O positivismo sociológico criminal teve como seu idealizador Enrico Ferri, advogado e professor, sendo considerado como o criador da sociologia criminal. Sua obra: "Sociologia Criminal-1884". 
Enrico Ferri deu ênfase não somente aos fatores antropológicos, como também aos físicos e sociais, destacando assim como a existência do trinômio causal do delito.

Diferentemente dos clássicos, Ferri negou o livre-arbítrio (mera ficção) como base $\mathrm{da}$ imputabilidade, entendendo que a responsabilidade moral deveria ser substituída pela responsabilidade social e que a razão de punir é a defesa social.

Autor da lei da saturação criminal, Ferri dizia que esta era a influência dos fatores criminógenos de cunho social na conduta delitiva, procedente do meio cultural onde vive o delinquente. Podemos citar como exemplo, nos dias atuais, a criança moradora de comunidade dominada pelo trafico, que cresce achando a criminalidade ali empregada um fator relativamente normal.

O método indutivo experimental e a estatística foram utilizados por Ferri junto ao estudo da criminologia. Diante disto, as suas teses constituem-se em reais acontecimentos de fato.

Ferri classificou os delinquentes como: Nato, louco, habitual, ocasional e passional.

Ao conceituar e definir a criminologia, parte da idéia do chamado positivismo jurídico criminal.

\footnotetext{
Etimologicamente, a palavra criminologia deriva do latim "crimino" (crime) e
}

do grego "logos" (estudo, tratado), significando o "estudo do crime".

Para o mestre Antônio Pablos de Molina, "a criminologia é a ciência empírica e interdisciplinar que se ocupa do estudo do crime, da pessoa do infrator, da vitima e do controle social do comportamento delitivo e que trata de subministrar uma informação válida, constatada, sobre a gênese, dinâmica e variáveis principais do crime contemplando este como problema individual e como problema social - assim como sobre programas de prevenção eficaz do mesmo e técnicas de intervenção positiva no homem delinqüente e nos diversos modelos on sistemas de respostas do delito".

A palavra criminologia foi divulgada internacionalmente pelo Juiz de direito italiano, Rafael Garófalo, em sua obra "Criminologia" (publicado em 1885/Milão).

Garófalo foi o precursor da fase jurídica do positivismo criminológico, onde empregou a tese de que a criminologia é uma ciência diversa do direito penal. Defendia a aplicação da pena de morte aos delinquentes irrecuperáveis ou a expulsão do país.

Ainda mais, idealizou uma concepção do delito natural, partindo da idéia Lombrosiana, como uma falha moral de caráter do criminoso que compromete a bondade humana, caracterizando assim o delinquente nato.

Compartilhava a ciência desenvolvida por Cesar Lombroso e os estudos realizados por Enrico Ferri, com a idéia que uma completava a outra. 
A sua classificação do homem delinquente era: assassinos, enérgicos ou violentos, ladrões ou neurastênicos.

Para Garófalo existiam duas hipóteses para tratamento dos delinquentes:

- Aos sujeitos que comentem crimes legais, estabelecidos em regulamentos ou códigos, bastava uma simples advertência e a obrigação na reparação do dano;

- Para aos que cometem crimes naturais, ou seja, próprios de delinquência nata, seriam penalizados com a morte.

Assim, conclui-se que a criminologia nasceu com Beccaria, surgindo cientificamente com Lombroso e reconhecida internacionalmente com Garófalo.

Em um breve conceito mais amplo da criminologia contemporânea, pode-se dizer que é uma ciência empírica (método científico-indutivo) e interdisciplinar, que tem por objeto a análisedo crime, a personalidade do autor do comportamento criminoso, a vítima e o controle social, com fulcro na compreensão dos fatores criminógenos que impulsionam a delinquência, traçando metas preventivas de combate à criminalidade.

Outro fator importante e contribuidor para a criminologia até os dias atuais, foi a elaboração da Estatística criminal, tendo seu precursor Adolphe Quetelet, matemático Belga e autor da obra: "Física Social - 1835".
Quetelet sustentava que o delito é um fenômeno social e que vários fatores são influentes para o cometimento do mesmo, como a miséria, o analfabetismo, o clima e etc.

Baseado nessas teorias, principalmente que o crime é um fenômeno concreto que só pode ser estudado por meios estatísticos, surge a criação das chamadas "Leis Térmicas de Quetelet”.

Essa criação trás como fundamento as diferentes probabilidades dos atos delitivos ocorridos nas estações do ano.

No Inverno se cometem mais delitos contra o patrimônio, entendendo que nesta época do ano são maiores as necessidades para a sobrevivência humana.

Os delitos contra os costumes são mais frequentes na primavera, onde libido e a boa sensação são probabilidades para acontecimento destes.

No verão ocorrem mais crimes contra a pessoa, pois, por conta do calor, as pessoas ficam mais propensas à agressividade, ao alto consumo de bebidas alcoólicas e à efervescência maior das paixões humanas. 
Tríplice Aliança: A Criminologia, Direito

Penal E Política Criminal Frente Ao

\section{Crime E Controle Social}

Houve tempo em que a criminologia se ocupava pela pesquisas de Beccaria, seguindo pela constatação do delinquente na Escola positiva. Rumo à década de 1950, traçou o estudo das vítimas e também mecanismos de controle social. Atualmente o objeto da criminologia esta dividido em quatro vertentes (delito, delinqüente, vítima e controle social), e no objeto crime e controle social que iremos destacar mais a frente.

Em resumo, tanto a criminologia quanto o direito penal se destinam a estudar o crime, porém as duas ciências se dedicam em visões diferentes para o fenômeno delitivo. A criminologia vê o crime como uma problemática social e individual, retratando o mesmo enquanto fato de forma explicativa na óptica de sua ciência. Já o direito Penal é uma ciência normativa que visa o crime como um comportamento anormal junto à categoria de infrações penais, fixando sanções àqueles que os praticam e, conceituando este como conduta (ação ou omissão) típica, antijurídica e culpável.

Ainda mais, a criminologia visa também conhecer a pessoa do criminoso, entendendo os fatores que o determinam para pratica do delito. Preocupa-se em realizar esquemas que combatam a criminalidade e a elaboração de meios preventivos.
A criminologia tem caráter preventivo, com estudo empírico, onde busca conhecer a realidade através de diagnosticar o crime e a tipologia do criminoso (ciência do ser). Enquanto o direito penal tem caráter meramente repressivo, fazendo proteção dos bens tutelados por meio de sanções penais, preocupando-se unicamente com a dogmática e sem interesse na realização de qualquer diagnóstico que possam impulsionar o comportamento delitivo.

Rogério Sanches menciona que " $a$ finalidade do direito penal está na análise dos fatos bumanos indesejados, definindo quais devem ser rotuladas como infrações penais e aplicando as respectivas sanções. Indica o crime enquanto norma.Já a criminologia é a ciência empírica que analisa o crime, a pessoa do criminoso, a vítima e o comportamento da sociedade. Visa o crime como fato".

\section{O Crime No Brasil}

No Brasil, a prática delituosa vem crescendo assustadoramente a cada ano. Podemos dizer que já faz parte do nosso cotidiano. Na maioria delas são os crimes contra o patrimônio e crimes contra as pessoas.

São muitos os noticiários que surgem em relação à violência no país e no mundo. Contudo, todos os dias diversas fontes mencionam o problema até a chegada no universo de nossos lares. 
Segundo uma publicação da revista Veja em 2014, o Brasil encontrava-se na $11^{\circ}$ posição dos países menos seguros do mundo, estando à frente de países como Quênia, Paquistão, Israel, Ucrânia e etc. Esta estatística reflete nos dias atuais.

\section{http://veja.abril.com.br/blog/impavido-} $\underline{\text { colosso/indice-aponta-brasil-como-11-pais- }}$ mais-inseguro-do-mundo/

Recentemente o blog Estadão Rio publicou uma matéria advertindo que o Brasil é líder Mundial em homicídios. Só no ano de 2012, como exemplo, ocorreram mais de 56 mil homicídios no país, ultrapassando como citado, países que vivem em Guerra.

http://brasil.estadao.com.br/blogs/estadaorio/brasil-lidera-em-numero-de-homicidiosmostra-ferramenta-virtual/

O que leva uma grande massa de insegurança no país? Quais os fatores que impulsionam para o crescimento da criminalidade? Quais as medidas de políticas criminais?

Os fatores geradores que ajudaram a colocar o Brasil na lista dos países mais inseguros do mundo são diversos, com pontos complexos a serem debatidos, mas determinantes para tal analise. Como exemplos, versam no crescimento populacional acelerado, surgimento em massa dos conglomerados e favelas, distribuição de renda insuficiente, falta de planejamento familiar e ate mesmo a problemática do menor.
A real situação é que a sociedade está exposta no geral e são diversos fatores que impulsionam a criminalidade. Podemos destacar ainda a desestruturação familiar, a educação, o saneamento básico, o desemprego, a falta de políticas públicas voltadas aos jovens (tese defendida pelos críticos da não redução da maioridade penal), desigualdade social, impunibilidade, segregação social, corrupção e etc.

No que tange a esses fatores, verificamos que os mesmos são diversos e que a criminalidade não atua de forma espontânea. As suas causas são concorrentes e o surgimento de um depende de outro. Vejamos a análise da desestruturação familiar, em que um jovem não tem amor, carinho e orientações dos seus pais, ou seja, princípios familiares. Estes ficam mais propensos a caírem no submundo do crime, no uso de drogas e etc.

\section{A Política Criminal E Sua Importância No Combate A Criminalidade No Brasil}

Surgindo como um conjunto sistemático de princípios e estratégias, a política criminal visa medidas solucionadoras, sugerindo reforma das normas e melhor aparato estatal frente à luta dos alarmantes índices de criminalidade. Reluz ao Estado a responsabilidade na aplicação da política criminal através de políticas públicas de segurança. 
Cabe à política criminal, todavia, optar por interesses e ideologias diretivas ao tratamento reservado da enfermidade social que é o crime. Além de elaborar estratégias de combate, é de suma relevância a promoção na execução destas.

Para Rogério Sanches, "a Politica Criminal tem no seu âmago a especifica finalidade de trabalhar as estratégias e meio de controle social da criminalidade. Caracteriza a posição de vanguarda em relação ao direito vigente, vez que, enquanto ciência de fins e meios, sugere e orienta reformas à legislação positivada".

Segundo Nilo Batista, "a política criminal é considerada um conjunto de princípios e recomendacões destinadas à reforma da legislação penal e transformação dos órgãos encarregados de sua aplicabilidade. Tais princípios são obtidos através das constantes mudanças sociais, das análises dos sistemas penais passados e aqueles ainda vigentes, com revelações empiricas das instituições penais, idealizando avanços e descobertas da criminologia. Ainda suplementa o autor que a Política Criminal pode ser dividida conforme sua concentração em cada etapa do sistema penal. Assim, podemos falar em política de segurança pública (foco na instituição policial), política judiciária (foco na instituição judicial) e política penitenciária (foco na instituição prisional)".

Vale ressaltar que, na Política Criminal, o Estado através de seu ânimo legislativo no combate às infrações penais, deve mencionar os bens juridicamente tutelados pelo direito penal. Opera em dois sentidos como regra do Estado de direito. O primeiro mencionando, através de sua atividade legislativa, os bens jurídicos penalmente relevantes e, depois, aplicando a norma penal, restringindo-se aos limites do mesmo. Cabe à Política Criminal, todavia, optar por interesses e ideologias diretivas do tratamento reservado da enfermidade social que é o crime, elaborar medidas e maneiras para seu combate.

A política criminal tem como precursor Franz Von Lizst, com sua obra: "Principio da Politica criminal-1889”.

Von Lizst ampliou na conceituação das ciências penais a criminologia como explicação das causas do comportamento delituoso e a penologia como causas e efeitos da pena.

Para Lizst, a política criminal nasceu na Itália no século XVIII, fundamentalmente com o surgimento da publicação da obra de Beccaria e sua preocupação com as eficazes formas junto à prevenção do delito e a questão legislativa capaz de alcançar tal finalidade.

\section{O Controle social e seus agentes como atuação das políticas criminais}

Como objeto da moderna criminologia, e sendo uma medida das políticas criminais, o controle social é um conjunto de instituições e estratégias que atuam no meio social, impondo ao individuo normas e regras de comportamento. É concretizado por meio de agentes de controle que visam à ordem pública através de disciplina social.

Quem são os agentes de controle e quais suas contribuições? 
Agentes de controle em sentido formal são identificados pelos órgãos e instituições de natureza coercitiva e punitiva, onde são representados pelo poder público, polícia, judiciário, sistema penitenciário e etc. Já os agentes de controle informal é o cotidiano das pessoas, buscando a socialização e educação através dos núcleos primários como a família, escola, igreja, amigos, profissão, situação econômica e etc.

Vale ressaltar que o controle formal atuará a partir do momento em que o controle informal não lograr socialização ou dirimir conflitos do sujeito junto ao cunho social.

Segundo a professora Mônica Gamboa, "o controle social ainda subdivide-se em controle social interno e externo, tendo em vista que o primeiro destinase ao controle das ações administrativas do Estado, diagnosticando sua legalidade. Justificado na ordem administrativa, política e jurídica, foca na promoção da autodisciplina social. No que tange o controle externo, este examina o exercicio de uma certa competência outorgada por lei, onde órgãos externos fiscalizam as atribuiçoes e funcionamento da administração pública, sendo utilizado na falta de autodisciplina social".

Diante do controle social, dentre muitas medidas adotadas, citamos como exemplo, dada sua grande importância, as chamadas unidades de polícia pacificadora.

\section{O Que São?}

A polícia pacificadora é uma medida inovadora na política de segurança pública, objetivando a aproximação entre os cidadãos e a polícia, fortalecendo as políticas sociais no ambiente comunitário carente.

Ademais, é um policiamento que aborda estratégias de aproximação, ação de presença, continuação, envolvimento e comprometimento comunitário na manutenção da ordem pública, da vida e dos bens das pessoas. A confiança recíproca estabelece um liame entre o cidadão e $\mathrm{o}$ agente de policia. O comprometimento policial é o incentivo, onde o sucesso depende de segmentos reativos e discretos das classes policiais, da observância do MP, da ação coativa judicial, da ressocialização do sujeito delinquente e, especialmente, as políticas de inclusão social, versando na educação e saúde para permanência e defesa dos esforços de todos contra a criminalidade. Seguindo pontos bem definidos por Bengochea.

Atualmente, o governo do Estado do Rio de Janeiro adere essa medida de policiamento comunitário, são as chamadas UPPs.

Mesmo com diversas falhas atuais, mas com vertentes em melhorias, as UPPs têm como foco à retomada dos territórios ocupados pelo poder coativo do tráfico de drogas ou milícias privadas, objetivando a garantia da cidadania e democracia nas comunidade carentes, 
devolvendo o direito de ir, vir e permanecer, lazer, trabalho e estudo que foram sucumbidos pela ausência do Poder Público e suas prestações na educação, saúde e segurança aos moradores.

As denominadas UPPs cariocas, como exemplo de policiamento de proximidade, projeta diretrizes como campanha educacional de resistência às drogas, junto às escolas e comércios da região; patrulhamentos ostensivos; contatos com lideranças locais através de reuniões dos conselhos de segurança do bairro e participação em eventos comunitários; administração de crises e adversidades locais, encaminhando-os caso não consiga solucionar; exercício pleno das atividades de policiamento, orientando, apaziguando e repreendendo condutas delitivas se necessário for, tendo em vista as principais propostas da referida política social de combate à criminalidade.

A polícia comunitária é uma filosofia de policiamento prevencionista, que lança seu olhar para a vítima e o controle social. As responsabilidades são divididas entre os órgãos de segurança pública e a sociedade. Parceria é a palavra-chave para implantação e êxito nesse processo. Tanto as instituições estatais, quanto a população local devem trabalhar para identificar, priorizar e resolver problemas que afetam a ordem e a paz social, tais como o crime, o medo, a exclusão e a desigualdade social que acentuam os problemas relativos à criminalidade e dificultam o propósito de melhorar a qualidade de vida dos cidadãos.

\section{Conclusão}

Diante do exposto, a idéia da causa que motiva a criminalidade não está elencada somente a um fator impulsionador, ou seja, o crime não decorre apenas de um determinado segmento. É uma abordagem difícil e complexa, pois a criminalidade no Brasil é fruto de determinados motivos que contribuem para esta problemática social.

O desenvolvimento de uma visão criminológica no Brasil é de grande morosidade. As razões para este comportamento e seus fatores motivadores devem ser analisados desde a opção ideológica da criminologia crítica até as dificuldades políticas internas enfrentadas, que ocasionam certo abatimento sócio-cultural.

Por fim, conclui-se que os objetos $\mathrm{da}$ moderna criminologia (o crime, criminoso, vítima e o controle social) têm que ser estudados tanto em relação normativa jurídica, quanto empírica. O crime por sua vez tem que ser disciplinado como objeto de estudo de previsibilidade e prevenção no direito penal. A Criminologia e o próprio direito penal têm que estar ligados para que as políticas criminais do Estado consigam, efetivamente, prevenir e controlar a criminalidade. 


\section{Referências}

BARATTA, Alessandro. Criminologia Crítica e Crítica do Direito Penal: Introdução à Sociologia do Direito penal, Rio de Janeiro: Freitas Bastos, 1999.

BATISTA, Nilo. Introdução crítica ao Direito Penal brasileiro. 11. ed. Rio de Janeiro: Revan, 2007

BENGOCHEA. Blog do policiamento comunitário. Disponível em http://policiamento comunitário.blogspot.com/20110201 archiv e.html.

BIANCHINI, Alice; MOLINA, Antonio García-Pablos de; GOMES, Luiz Flavio. Direito Penal - Introdução e Princípios Fundamentais. $2^{\circ}$ Ed., São Paulo: RT, 2009, vol1.

CALHAU, Lélio Braga. Resumo de Criminologia. $5^{\circ}$ Ed.,Niteroi: Impetus, 2010.

CUNHA, Rogério Sanches. Manual de Direito Penal - Parte Geral. $2^{\circ}$ Ed., Bahia:Juspodivm, 2014.

FERNANDES, Newton; FERNANDES, Valter. Criminologia Integrada. $4^{\circ}$ Ed., São Paulo : RT, 2012.

GAMBOA, Mônica Resende. Criminologia. $2^{\circ}$ Ed. rev., atual. e ampl. - Rio de Janeiro : Forense ; São Paulo : Método; 2013.
MOLINA, Antonio García-Pablos de; GOMES, Luiz Flávio. Criminologia, $4^{a}$ Ed., São Paulo, RT, 2002.

PENTEADO FILHO, Nestor Sampaio. Manual Esquemático de Criminologia, $3^{\circ}$ Ed., São Paulo: Saraiva, 2013. 